\title{
METAS DO CONSELHO NACIONAL DE JUSTIÇA E O DIREITO RESPONSIVO: UMA ANÁLISE NO TRIBUNAL DE JUSTIÇA DO ESTADO DE RONDÔNIA
}

\author{
Carolina Yukari Veludo Watanabe ${ }^{1}$ \\ Samile Dias Carvalho ${ }^{2}$
}

\section{Resumo}

O Conselho Nacional de Justiça (CNJ) é órgão de controle da atuação administrativa e financeira do Poder Judiciário e do cumprimento dos deveres funcionais dos juízes. Uma das medidas adotadas para o desempenho do seu papel é o estabelecimento de metas anuais comuns a todos os tribunais. Estas metas possuem foco na agilidade, responsabilidade social, modernização e priorização de julgamento. Contudo, o CNJ sofre diversas críticas, ao mesmo tempo em que há exigência de elaboração e implementação de políticas públicas para melhorar a prestação jurisdicional. Função conferida ao CNJ, assim, é necessário avaliar e analisar as políticas implantadas. Este trabalho busca analisar o modelo jurídico em que as metas propostas pelo CNJ estão inseridas, por meio de pesquisa qualitativa, exploratória e bibliográfica. Posteriormente, busca também a identificação do desempenho do Tribunal de Justiça do Estado de Rondônia (TJRO) de forma quantitativa, exploratória, descritiva e documental. Os resultados indicam que a implementação de metas pelo CNJ tem raízes no direito responsivo, sendo um movimento que oferece pequena participação da sociedade. O TJRO demonstrou ter um bom desempenho dentro das metas mais recorrentes, fruto do empenho de membros, servidores e administração.

Palavras-chave: Metas. CNJ.TJRO. Direito responsivo. Acesso à justiça.

\footnotetext{
${ }^{1}$ Doutora em Ciências de Computação e Matemática Computacional pela Universidade de São Paulo (ICMC-USP). Mestre em Ciências de Computação e Matemática Computacional (ICMC-USP) e bacharel em Matemática Aplicada e Computação Científica (ICMC-USP), com ênfase em Estatística. Atualmente é professora Adjunto III na Universidade Federal de Rondônia (UNIR), atuando nos programas de pós-graduação de Mestrado Profissional em Direitos Humanos e Desenvolvimento da Justiça e Mestrado em Administração. E-mail: carolina@unir.br

${ }^{2}$ Graduada em Direito, aluna do Programa de Pós-Graduação Mestrado Profissional em Direitos Humanos e Desenvolvimento da Justiça da Universidade Federal de Rondônia em convênio com a Escola da Magistratura do Estado de Rondônia. Especialista em Direito para carreira da magistratura na Escola da Magistratura do Estado de Rondônia em 2015. É servidora do Tribunal de Justiça do Estado de Rondônia desde o ano de 2009. E-mail: samile@unir.br
} 


\section{INTRODUÇÃO}

O direito de acesso à justiça é tão fundamental que chega a ser classificado como "elemento constitutivo do próprio exercício da cidadania, pois é esse direito que possibilita o exercício da cidadania quando o cidadão é arbitrariamente impedido de fruir determinado direito por causa do Estado" (ALMEIDA, 2012).

Em contraponto à importância e essencialidade do direito de acesso à justiça observam-se profundas insatisfações com o Poder Judiciário brasileiro. A principal reclamação diz respeito à demora nos julgamentos e/ou conclusão das demandas judiciais, considerada como lentidão e inoperância (ALMEIDA, 2012; CASTELLO BRANCO, 2013; DEMARCHI, 2011).

Diante do cenário de crise, em 2004, a Emenda Constitucional 45, conhecida como "Reforma do Judiciário" (TAVARES, 2005) trouxe nova formatação. Para tanto, mencionou na exposição de motivos que a administração da Justiça é problema que a todos interessa, já que as decisões dos juízes e tribunais são a última etapa da vida do Direito (BRASIL, 2004).

Dentro das mudanças apresentadas pela Emenda Constitucional n. 45 está a criação do Conselho Nacional de Justiça - CNJ, estabelecido no artigo 103-B da Constituição Federal, como órgão de controle da atuação administrativa e financeira do Poder Judiciário e do cumprimento dos deveres funcionais dos juízes (BRASIL, 2004).

Em seu sítio eletrônico o CNJ (CNJ, 2017a) cita como missão "contribuir para que a prestação jurisdicional seja realizada com moralidade, eficiência e efetividade em benefício da sociedade" e que visa "aperfeiçoar o trabalho do sistema judiciário brasileiro, principalmente no que diz respeito ao controle e à transparência administrativa e processual".

Uma das medidas adotadas para o desempenho do papel do CNJ é o estabelecimento de metas anuais comuns a todos os tribunais, desde o ano de 2009, por meio da Resolução n. 70/2009, que dispôs sobre o planejamento e a gestão estratégica no âmbito do Poder Judiciário (CNJ, 2009).

Desde então são elaboradas metas anuais e nacionais que atingem todos os tribunais do país. No início foram chamadas de metas de nivelamento para o judiciário; em 2010 passaram a ser estabelecidas também metas específicas para cada segmento de Justiça: Trabalhista, Federal, Militar, Eleitoral e Estadual (CNJ, 2017c).

As metas são definidas no Encontro Nacional do Judiciário e tem foco na agilidade e eficiência da Justiça, responsabilidade social, modernização, priorização de julgamento entre outros.

O sítio eletrônico do $\mathrm{CNJ}$ ainda divulga relatórios com os resultados obtidos pelos tribunais, além de explicar detalhadamente cada meta estabelecida no arquivo denominado Glossários e Esclarecimentos, em que especifica o critério de cumprimento e fórmula de cálculo (CNJ, 2017b). 
Contudo, desde a sua criação, o CNJ sofre diversas críticas, especialmente por parte do próprio Poder Judiciário, tanto que sofreu duas Ações Diretas de Inconstitucionalidade (ADI 3367 e 4638 - ambas propostas pela Associação dos Magistrados Brasileiros - AMB) (BRASIL, 2005; BRASIL, 2011).

Não se pode negar que o Judiciário hoje, mais do que nunca, está sob grande holofote. O avanço da tecnologia, a divulgação dos direitos e do próprio sistema de Justiça, tornou mais acessível um mundo antes tido como inacessível, seja a transmissão de sessão do Supremo Tribunal Federal - STF, casos de grande repercussão com o julgamento noticiado ou até mesmo transmitidos, ou ainda os movimentos de apoio a juízes como ao juiz Sergio Moro, condutor da Lava-Jato (CONSULTOR JURÍDICO, 2015). Tudo isso aproxima o Judiciário da população em geral.

Por todo esse conjunto, é necessário o desempenho do Judiciário como protagonista na elaboração e implementação de políticas públicas em sua própria esfera.

É interessante situar o CNJ dentro desse contexto. Para Freire, Bernardes e Rover (2011):

O CNJ configura-se como o epicentro das mudanças em curso no Sistema de Justiça, seja por suas competências amplas no que se refere ao controle, administração, elaboração de políticas públicas; seja por sua composição mais aberta que abriga seis membros externos ao judiciário, tendo uma composição total de quinze membros.

O CNJ insere-se, na Constituição Federal, como segundo órgão do Judiciário, só ficando abaixo do Supremo Tribunal Federal. Além disso, tal órgão tem imprimido mudanças substanciais no Sistema de Justiça.

Com o mesmo entendimento, Silva e Florêncio (2011) afirmam que, o CNJ desempenha importante papel de balizador das políticas judiciárias, orientando-as rumo à convergência de propósitos. Sustentam, ainda, que a busca de soluções aos problemas Judiciários, com base na ideia de que políticas públicas especificamente orientadas para o sistema judicial são relevantes para o próprio aperfeiçoamento da democracia.

Contudo, ainda assim, é necessário avaliar e analisar as políticas implementadas pelo CNJ para mensurar sua efetividade e responsividade. Boaventura de Souza Santos (2007, apud FREIRE, BERNARDES, ROVER, 2011) reconhece um protagonismo do judiciário em face da ampliação dos direitos sociais, o que implica tanto numa judicialização da política, como também, uma politização da justiça. Ainda, adverte que é preciso construir uma justiça cidadã, alicerçada numa cultura jurídica democrática para consolidar as mudanças iniciadas pela Reforma do Judiciário brasileiro.

Assim, considerando a necessidade de avaliação e reflexão quanto às políticas implementadas pelo CNJ, este trabalho buscou identificar, dentro do contexto sociedade, Estado e Direito, a natureza ou modelo jurídico em que as metas propostas pelo $\mathrm{CNJ}$ estão inseridas. Posteriormente, com o intuito de verificar o desempenho da justiça comum, investigou-se o Tribunal de Justiça do Estado de Rondônia quanto ao cumprimento das metas mais recorrentes desde a implantação no ano de 2009. 
A primeira parte da pesquisa caracteriza-se pela abordagem qualitativa, de natureza aplicada, exploratória e bibliográfica. No segundo momento, quanto ao desempenho do Judiciário de Rondônia, a pesquisa identifica-se como quantitativa, de natureza aplicada, quanto aos objetivos apresenta-se como exploratória e descritiva e de procedimentos técnicos documentais.

\section{MODELOS JURÍDICOS E AS METAS NACIONAIS DO CNJ}

A obra Direito e Sociedade: a transição ao sistema jurídico responsivo, de Philippe Nonet e Philip Selznick (2010), identifica três tipos de modelos jurídicos: direito repressivo, autônomo e responsivo, com características próprias, mas que podem coexistir, e geralmente assim ocorrem, numa mesma época na sociedade.

Cada modelo representa os traços do momento político e social que uma determinada comunidade vive e expressa dentro do seu complexo normativo. No entanto, a história demonstra certa direção de "evolução", que parte do Direito Repressivo, passando pelo Direito Autônomo e por fim alcançando o Direito Responsivo. O Quadro 1 apresenta uma síntese das características de cada um dos modelos, os quais são descritos a seguir.

Quadro 1.Caracterização dos modelos jurídicos

\begin{tabular}{|c|c|c|c|}
\hline $\begin{array}{c}\text { Características / } \\
\text { Modelos Jurídicos }\end{array}$ & Direito Repressivo & Direito Autônomo & Direito Responsivo \\
\hline $\begin{array}{c}\text { Principal } \\
\text { característica }\end{array}$ & $\begin{array}{c}\text { Ordem / Direito } \\
\text { subordinado ao poder } \\
\text { político }\end{array}$ & $\begin{array}{c}\text { Separação entre os } \\
\text { poderes; } \\
\text { Direito independente } \\
\text { da política }\end{array}$ & $\begin{array}{c}\text { Integração de aspirações legais e } \\
\text { políticas (espécie de continuação } \\
\text { entre os poderes) }\end{array}$ \\
\hline Sistema normativo & $\begin{array}{c}\text { Pouco elaborado; } \\
\text { Não alcança } \\
\text { governantes }\end{array}$ & $\begin{array}{c}\text { Elaborado; } \\
\text { Alcança governantes e } \\
\text { governados }\end{array}$ & $\begin{array}{c}\text { Subordinado à princípios e a políticas } \\
\text { institucionalizadas }\end{array}$ \\
\hline Coerção & $\begin{array}{c}\text { Com poucos limites } \\
\text { Controlada por limites } \\
\text { legais }\end{array}$ & $\begin{array}{c}\text { Busca de alternativas baseadas em } \\
\text { incentivos pedagógicos }\end{array}$ \\
\hline Desobediência & Punida como rebeldia & $\begin{array}{c}\text { Justificada apenas com } \\
\text { amparo legal } \\
\text { Limitado pelos } \\
\text { procedimentos } \\
\text { estabelecidos }\end{array}$ & $\begin{array}{c}\text { Avaliada em termos de danos efetivos } \\
\text { Participação do }\end{array}$ \\
acesso & Baixa & $\begin{array}{c}\text { grupos defensores de causas sociais e } \\
\text { da esfera judicial }\end{array}$ \\
\hline
\end{tabular}

Fonte: Elaboração própria a partir de Philippe Nonet e Philip Selznick (2010).

As principais características do Direito Repressivo, de acordo com o texto, dizem respeito a finalidade do direito como a ordem, justificada pela busca de segurança social e razão de Estado, com o sistema normativo pouco elaborado, incapaz de alcançar os governantes, coerção com poucos limites, desobediência punida como rebeldia, baixa participação social, obrigada ao consentimento passivo e qualquer crítica é vista como manifestação 
de deslealdade. A principal característica política é o direito estar subordinado ao poder político. Tal modelo é típico dos governos autoritários, como o militarismo no Brasil.

Entretanto, suas marcas ainda permanecem mesmo que quando outros modelos predominam na sociedade, como é o caso das delegacias de polícia brasileiras, que ainda apresentam "traços de uma polícia de atuação arbitrária e autoritária, característica de sistemas jurídicos repressivos" (RIBEIRO E MACHADO, 2014).

O segundo modelo apresentado, o Direito Autônomo, tem como principal característica política, o direito independente da política, em uma separação entre os poderes, decorrendo daí sua preocupação com a legitimação, procedimentos equânimes, com sistema normativo elaborado, sujeitando tanto governantes como governados. A coerção é controlada por limites legais, a desobediência é justificada apenas com amparo legal, e a participação do acesso é limitado pelos procedimentos estabelecidos.

Esse parece ser o sistema que atualmente predomina no Brasil. Exemplo disso é a aplicação da autocontenção, quando o judiciário tem a atuação limitada para determinada situação, assim como utilizado no julgado abaixo:

(...) o Supremo Tribunal Federal somente deve intervir em procedimentos legislativos para assegurar o cumprimento da Constituição, proteger direitos fundamentais e resguardar os pressupostos de funcionamento da democracia e das instituições republicanas. Exemplo típico na jurisprudência é a preservação dos direitos das minorias. Em se tratando de processos de cunho acentuadamente político, como é o caso da cassação de mandato parlamentar, a Corte deve se pautar pela deferência e pela autocontenção, somente intervindo em casos excepcionalíssimos. (...) (STF. MS 34327, Relator(a): Min. ROBERTO BARROSO, Tribunal Pleno, julgado em 08/09/2016, PROCESSO ELETRÔNICO DJe-168 DIVULG 31-07-2017 PUBLIC 01-08-2017) (BRASIL, 2016)

Por fim, o Direito Responsivo apresenta integração de aspirações legais e políticas, numa espécie de continuação entre os poderes. A finalidade do direito é a competência como capacidade de resolver problemas e, por isso, se preocupa com a justiça substantiva, a justificação dos fins torna a discricionariedade ampla, há uma busca de alternativas para coerção baseadas em incentivos pedagógicos, a desobediência é avaliada em termos de danos efetivos. Quanto a participação tem acesso ampliado pela integração dos grupos defensores de causas sociais na esfera política com os grupos que atuam com o mesmo propósito na esfera judicial, e o sistema normativo é subordinado à princípios e a políticas institucionalizadas.

Para exemplificar esse modelo que confere maior liberdade ao judiciário é que surgem temas como judicialização, ativismo e abertura pelos princípios (ARRABAL, DIAS E ZENI DE SÁ, 2014).

Dentro deste contexto indaga-se sobre a adoção de metas nacionais pelo CNJ: tal medida pertence ao rol do Direito Responsivo?

Para ilustrar, a seguir estão transcritas as metas nacionais do ano de 2017, disponíveis no sítio eletrônico do CNJ (2016a): 
META 1 - Julgar mais processos que os distribuídos (Todos os segmentos)

META 2 - Julgar processos mais antigos (Todos os segmentos)

META 3 - Aumentar os casos solucionados por conciliação (Justiça Federal e Justiça do Trabalho)

META 4 - Priorizar o julgamento dos processos relativos à corrupção e à improbidade administrativa (STJ, Justiça Estadual, Justiça Federal e Justiça Militar da União e dos Estados)

META 5 - Impulsionar processos à execução (Justiça Estadual, Justiça Federal e Justiça do Trabalho)

META 6 - Priorizar o julgamento das ações coletivas (STJ, TST, Justiça Estadual, Justiça Federal e Justiça do Trabalho)

META 7 - Priorizar o julgamento dos processos dos maiores litigantes e dos recursos repetitivos (STJ, TST, Justiça do Trabalho)

META 8 - Fortalecer a rede de enfrentamento à violência doméstica e familiar contra as mulheres (Justiça Estadual)

Grande parte das metas é repetida no próximo ano com algumas modificações específicas, por exemplo, no ano de 2016 a meta 2 (Julgar processos mais antigos) compreendia para a Justiça Estadual o julgamento de $80 \%$ dos processos distribuídos até 31/12/2012 no $1^{\circ}$ grau, 80\% dos processos distribuídos até 31/12/2013 no $2^{\circ}$ grau, e 100\% dos processos distribuídos até 31/12/2013 nos Juizados Especiais e Turmas Recursais, enquanto que no ano de 2017 espera-se julgar na Justiça Estadual 80\% dos processos distribuídos até 31/12/2013 no 1º grau, $80 \%$ dos processos distribuídos até 31/12/2014 no 20 grau, e 100\% dos processos distribuídos até 31/12/2014 nos Juizados Especiais e Turmas Recursais (CNJ, 2015).

Para o ano de 2016 houve a interessante meta nacional de número 8 de implementar práticas de Justiça Restaurativa, destinada à Justiça Estadual, assim especificada: implementar projeto com equipe capacitada para oferecer práticas de Justiça Restaurativa, implantando ou qualificando pelo menos uma unidade para esse fim, até 31.12.2016 (CNJ, 2015).

Para 2018, o CNJ inova na construção das metas nacionais promovendo processos participativos em parceria com os tribunais brasileiros, buscando a opinião de magistrados, servidores, associações de classe e da sociedade. A participação está prevista na Resolução n. 221/2016, que concede até o mês de agosto para os tribunais colherem as sugestões (CNJ, 2016b).

As formas que os tribunais podem utilizar para realizar a consulta incluem workshops, consultas públicas, pesquisas internas, reuniões temáticas ou discussões com grupos focais. As propostas podem sugerir a criação e a alteração de metas (CIEGLINSKI, 2017).

O Tribunal de Justiça do Estado de Rondônia lançou consulta pública em seu portal na internet entre os dias 3 e 4 de julho de 2017. A notícia de divulgação no portal do TJRO destacou que servidores, magistrados, parceiros da Justiça como defensores, promotores e advogados, deviam participar da consulta e que todos os cidadãos interessados estavam convidados a contribuir. Os resultados serão debatidos no Comitê da Justiça Estadual e depois no Encontro Nacional do Poder Judiciário, em novembro de 2017 (RONDONIA, 2017a). 
Assim, a abertura para participação da sociedade ficou ainda mais clara e acessível com a Resolução n. 221/2016 do CNJ em que permite que o cidadão, ligado diretamente ao Judiciário ou não, proponha alteração ou criação de meta para o ano de 2018, o que representa grande avanço.

Neste ponto, cabe ressaltar a mudança de paradigma ao aproximar o cidadão ao Judiciário:

Importa referir ainda, que a abertura de canais de comunicação com o cidadão, no âmbito do Sistema de Justiça é salutar, principalmente, por este Sistema sofrer historicamente de insulamento em relação não só da sociedade, mas também dos órgãos do Estado. O Sistema de Justiça é visto como um setor de controle, pois é o único que não está associado a nenhum tipo de controle pelo voto, com o Poder Executivo ou Legislativo (FREIRE, BERNARDES E ROVER, 2011).

Esse distanciamento entre Direito e Política, com marcante separação entre os poderes, é característica do Direito Autônomo, sendo a aproximação o caminho para o Direito Responsivo.

Portanto, "a consolidação das políticas judiciárias tem o potencial de transformar as feições tradicionais da justiça no modo de se relacionar com a sociedade e de exercer seu papel protagonista e estratégico de forma mais responsiva" (SILVA E FLORÊNCIO, 2011).

Assim, pode-se afirmar que a implementação de metas anuais pelo CNJ tem raízes no direito responsivo, sendo um movimento interno do Poder Judiciário que oferece abertura, ainda que pequena, para a participação da sociedade, que pode expressar o que mais anseia pelo Judiciário atual, cabendo ao $\mathrm{CNJ}$ gerir as expectativas e promover a discussão entre os tribunais do país.

\section{DESEMPENHO DO TRIBUNAL DE JUSTIÇA DO ESTADO DE RONDONIA}

Considerando a relevância do movimento de implementação das metas pelo $\mathrm{CNJ}$ e que para a sua efetividade são necessários os esforços dos tribunais e seus componentes, incluindo membros e servidores, indagase sobre o desempenho do Tribunal de Justiça do Estado de Rondônia.

Para esta pesquisa foi considerado o período de 2009 a 2017, e foram utilizadas as metas mais recorrentes, como o julgamento de quantitativo maior do que o de processos distribuídos, o julgamento de processos mais antigos, de ações coletivas e de ações que combatem a improbidade administrativa e corrupção (nomeadas como meta 1,2,6 e 4 respectivamente).

Como mencionado anteriormente, as metas foram implementadas no ano de 2009, no entanto, em sua maior parte tratavam sobre nivelamento como capacitação e informatização. A partir de 2010 passaram a ser estabelecidas também metas específicas para cada segmento de Justiça (Trabalhista, Federal, Militar, Eleitoral e Estadual). De uma forma geral, as metas priorizam os julgamentos de temas/causas importantes para a sociedade e buscam garantir os direitos de cidadania, como o fortalecimento da rede de enfrentamento à violência doméstica 
e familiar contra as mulheres e a implementação da justiça restaurativa, por exemplo.

Uma das metas mais recorrentes e conhecida, quase sempre nomeada como meta 1, especificada como: julgar mais processos que os distribuídos, esteve presente em quase todos os anos, com exceção do ano de 2009. O desempenho do TJRO com relação a esta meta, com os dados obtidos pelo site do CNJ, é expresso no Gráfico 1.

Gráfico 1. Porcentagem do cumprimento da Meta 1 pelo TJRO de 2011 a 2017.

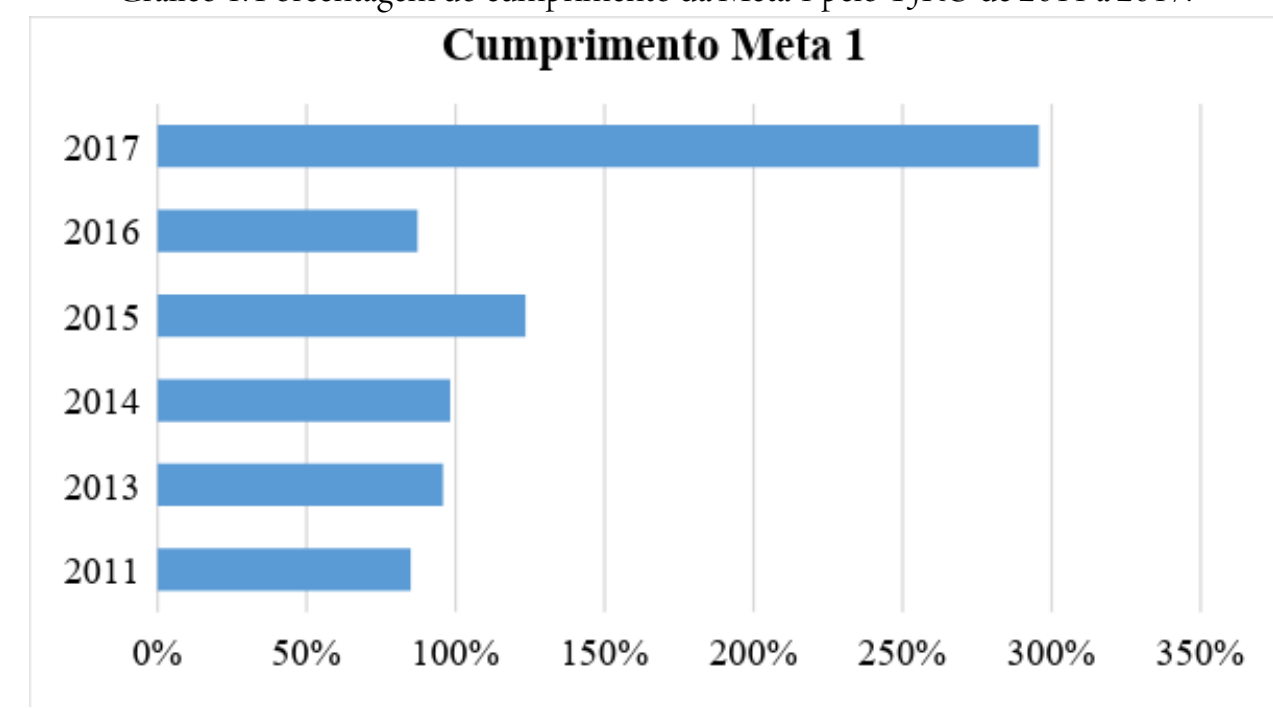

Fonte: Elaboração própria a partir de dados do CNJ (2017).

A segunda meta aqui descrita, do julgamento dos processos mais antigos, intitulada como meta 2, esteve presente em quase todas as edições, com exceção do ano de 2011 . O principal objetivo dessa meta é que a maioria dos processos (80\%) tenham julgamento, incluindo os recursos em segundo grau, no máximo em 4 anos. E que os processos em primeiro grau, em sua maioria (80\%) tramitem no máximo por 3 anos.

Os dados divulgados no CNJ, a partir do ano de 2014, dividem o desempenho dos tribunais em primeiro e segundo grau. Antes era apresentado um único número, compreendendo as duas instâncias de cada tribunal, deste modo era divulgado apenas um resultado para todo o tribunal. Assim, para esta pesquisa foram confeccionados dois gráficos, um para o primeiro e outro para o segundo grau, no entanto, repetiu-se os percentuais atingidos em 2009, 2010, 2012 e 2013 para ambos. Os resultados estão dispostos nos Gráficos 2 e 3: 
Gráfico 2. Porcentagem de cumprimento da Meta 2 pelo $1^{\circ}$ grau do TJRO de 2009 a 2017.

\section{Cumprimento Meta 2 - 10 grau}

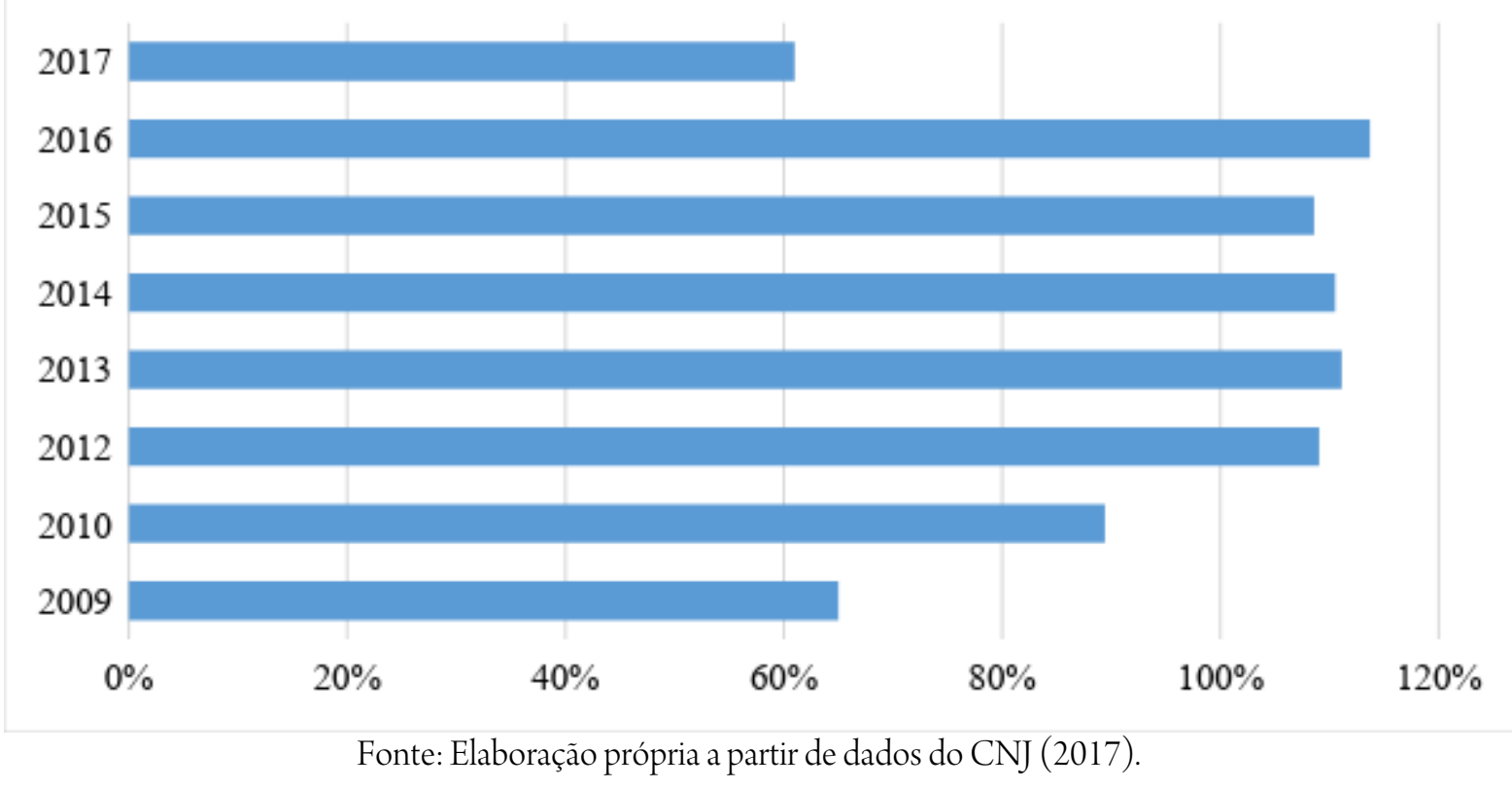

Gráfico 3. Porcentagem de cumprimento da Meta 2 pelo 2 grau do TJRO de 2009 a 2017.

\section{Cumprimento Meta 2 - 20 grau}

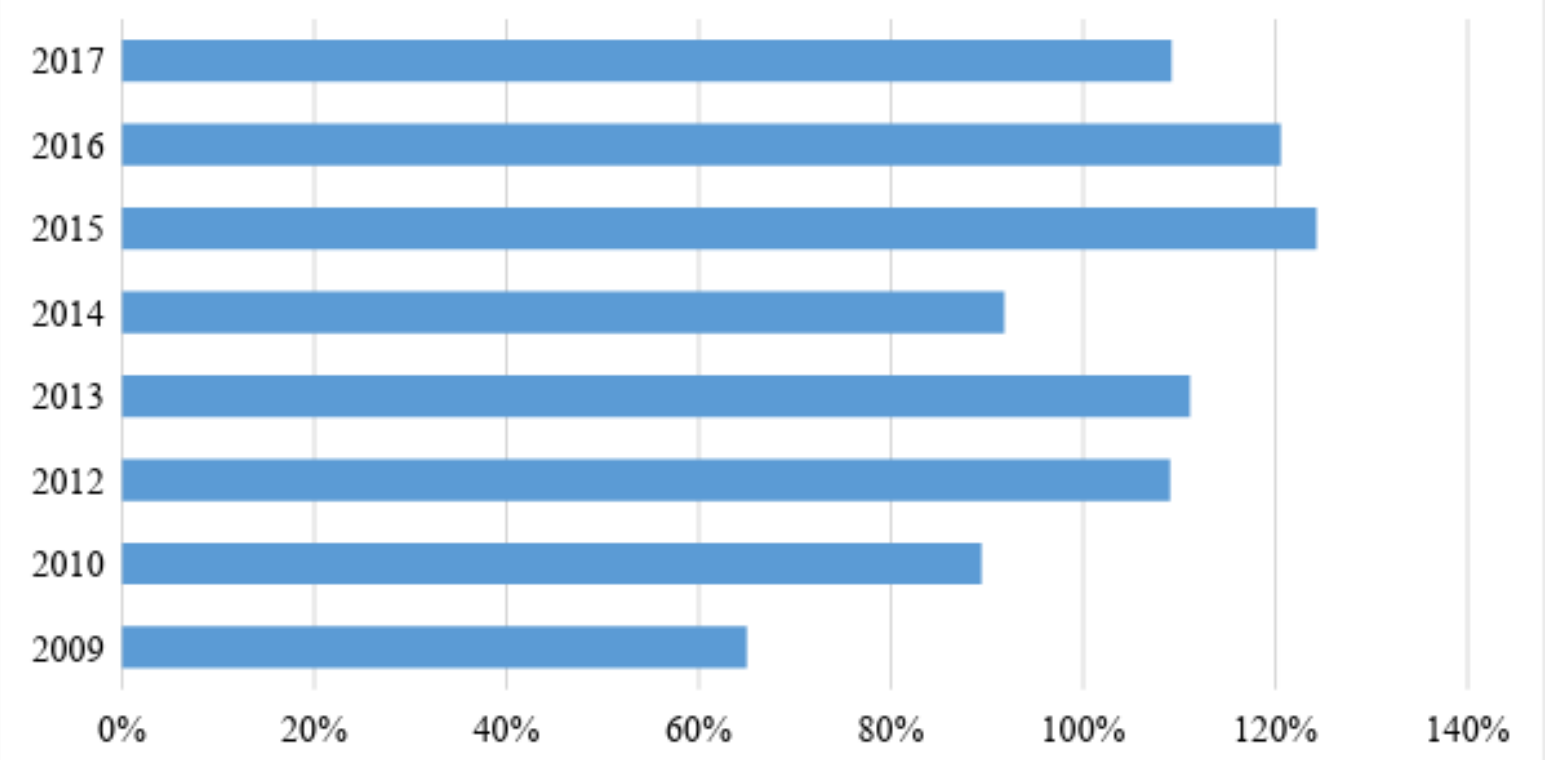

Fonte: Elaboração própria a partir de dados do CNJ (2017).

A partir do ano de 2014, refletindo a indignação popular, o CNJ lançou a meta 4, que prioriza o julgamento dos processos relativos à corrupção e à improbidade administrativa e está dividida em três partes: improbidade administrativa, crime contra a administração pública e combate à corrupção. Nela, busca-se que a maioria $(70 \%)$ dos processos destacados tenham julgamento no máximo em três anos.

Interessante notar que as metas anteriores fazem referência principalmente a tempo de julgamento, 
buscando especialmente atingir a duração razoável do processo, até mesmo em cumprimento ao comando constitucional estabelecido no art. 5º, LXXVIII da CF/88 (BRASIL, 1988), no entanto, sem especificar a matéria dos processos, ou seja, o critério é apenas temporal.

A partir de 2014, por meio da meta 4, a prioridade não reside apenas no critério temporal, mas também em determinadas classes ou tipos de processos, quais sejam, os que combatem improbidade administrativa, crime contra a administração pública e à corrupção, as matérias escolhidas refletem o atendimento aos reclamos populares.

Deste modo, para esta pesquisa foram confeccionados três gráficos, um para cada para matéria, os Gráficos 4, 5 e 6 demonstram o desempenho do TJRO.

Gráfico 4. Porcentagem de cumprimento da Meta 4 - Improbidade Administrativa pelo TJRO de 2014 a 2017.

\section{Cumprimento Meta 4 - Improbidade administrativa}

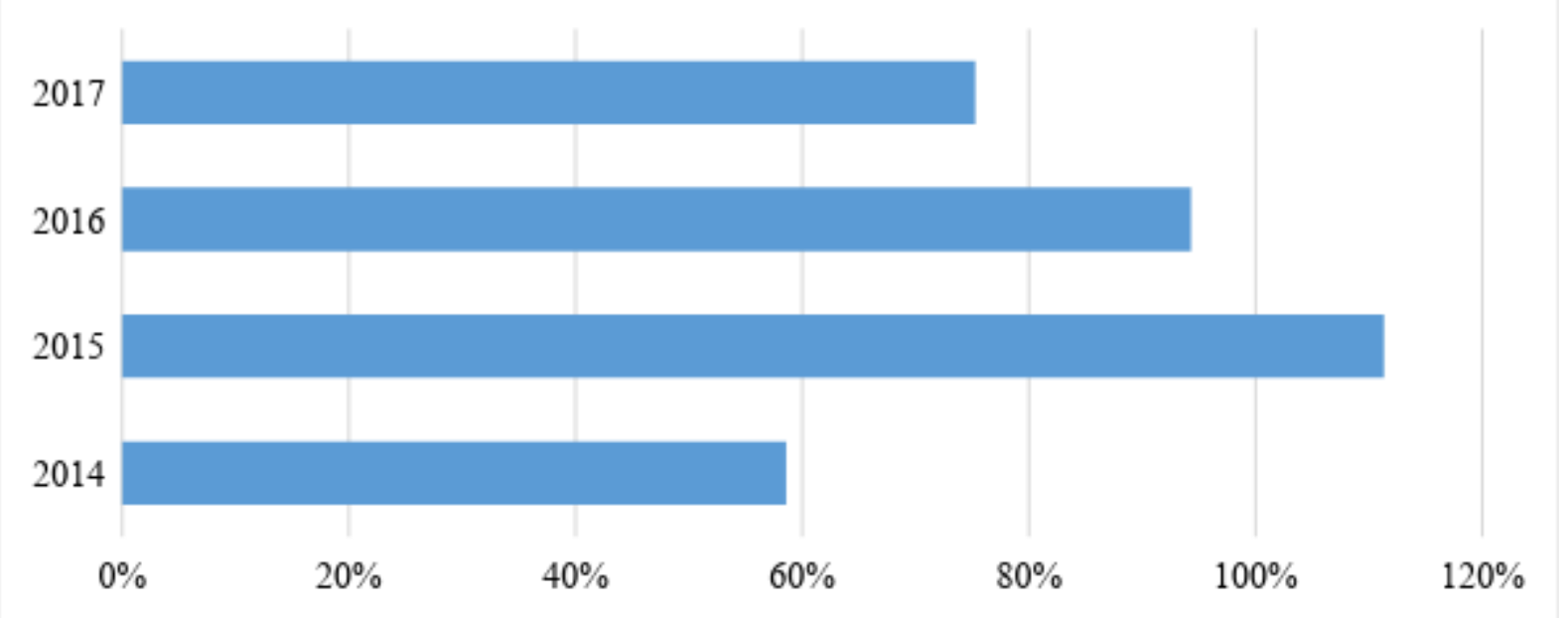

Fonte: Elaboração própria a partir de dados do CNJ (2017).

Gráfico 5. Porcentagem de cumprimento da Meta 4 - Crime contra a Administração Pública pelo TJRO de 2014 a 2017. 


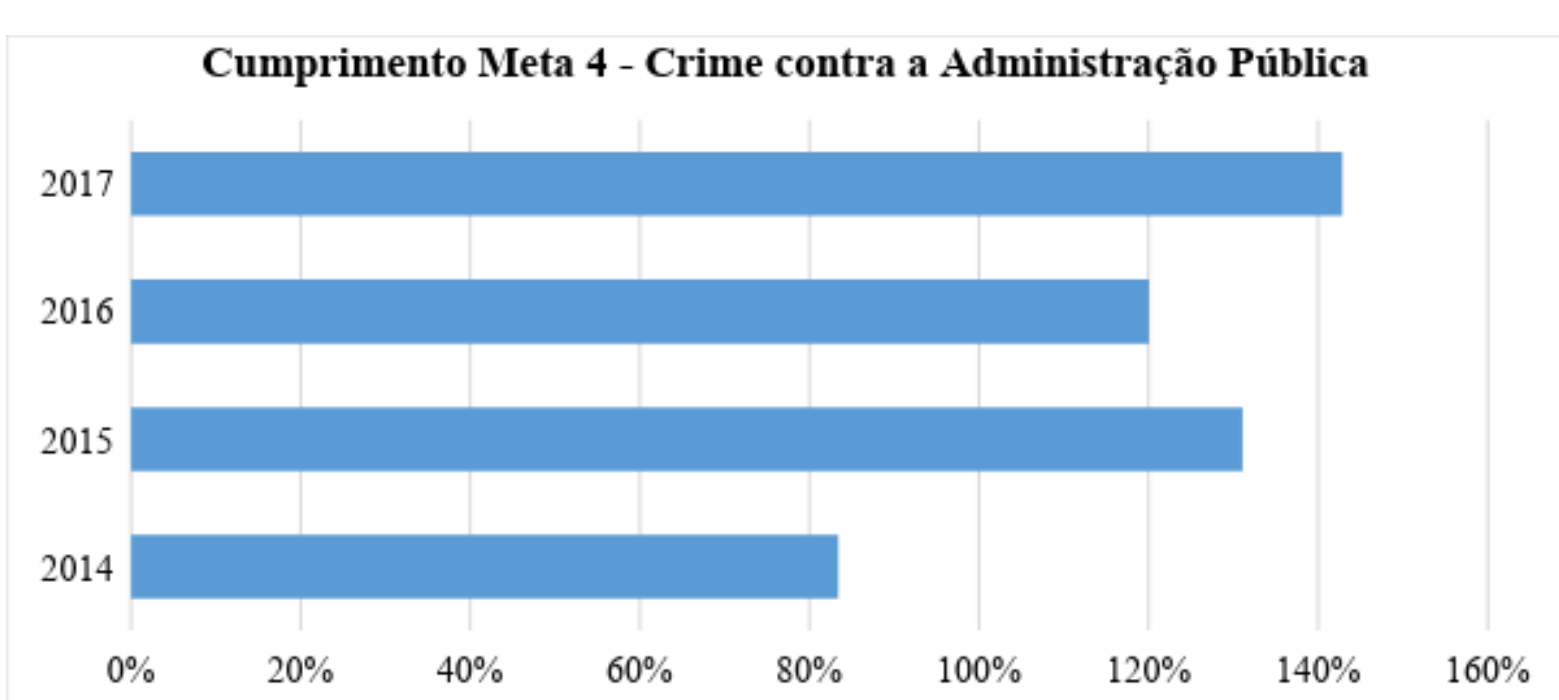

Fonte: Elaboração própria a partir de dados do CNJ (2017).

Gráfico 6. Porcentagem de cumprimento da Meta 4 - Combate à Corrupção pelo TJRO de 2014 a 2017.

\section{Cumprimento Meta 4 - Combate à corrupção}

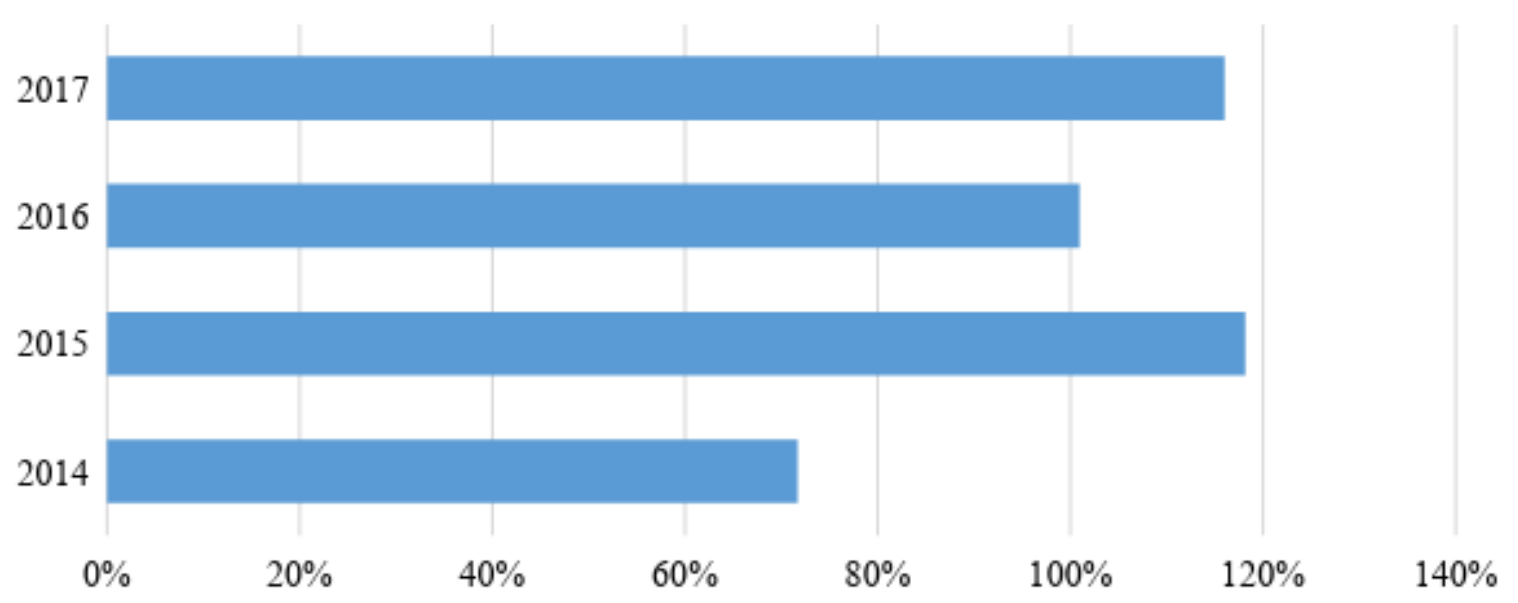

Fonte: Elaboração própria a partir de dados do CNJ (2017).

Outra meta que também foi iniciada em 2014 é a denominada meta 6, que prioriza o julgamento das ações coletivas, que pela própria denominação atinge grande número de pessoas, justificando a relevância da prioridade. Seu objetivo é que 60\% dos processos sejam julgados em até três anos no primeiro grau e que 80\% sejam julgados em até dois anos no segundo grau.

Os dados do $\mathrm{CNJ}$ dividem o desempenho dos tribunais em primeiro e segundo grau, por essa razão foram gerados dois gráficos para apresentar o desempenho do TJRO quanto a meta 6, dos anos de 2014 a 2017, os resultados estão dispostos nos Gráficos 7 e 8 . 
Gráfico 7. Porcentagem de cumprimento da Meta 6 pelo $1^{\circ}$ grau do TJRO de 2014 a 2017.

\section{Cumprimento Meta 6 - 10 grau}

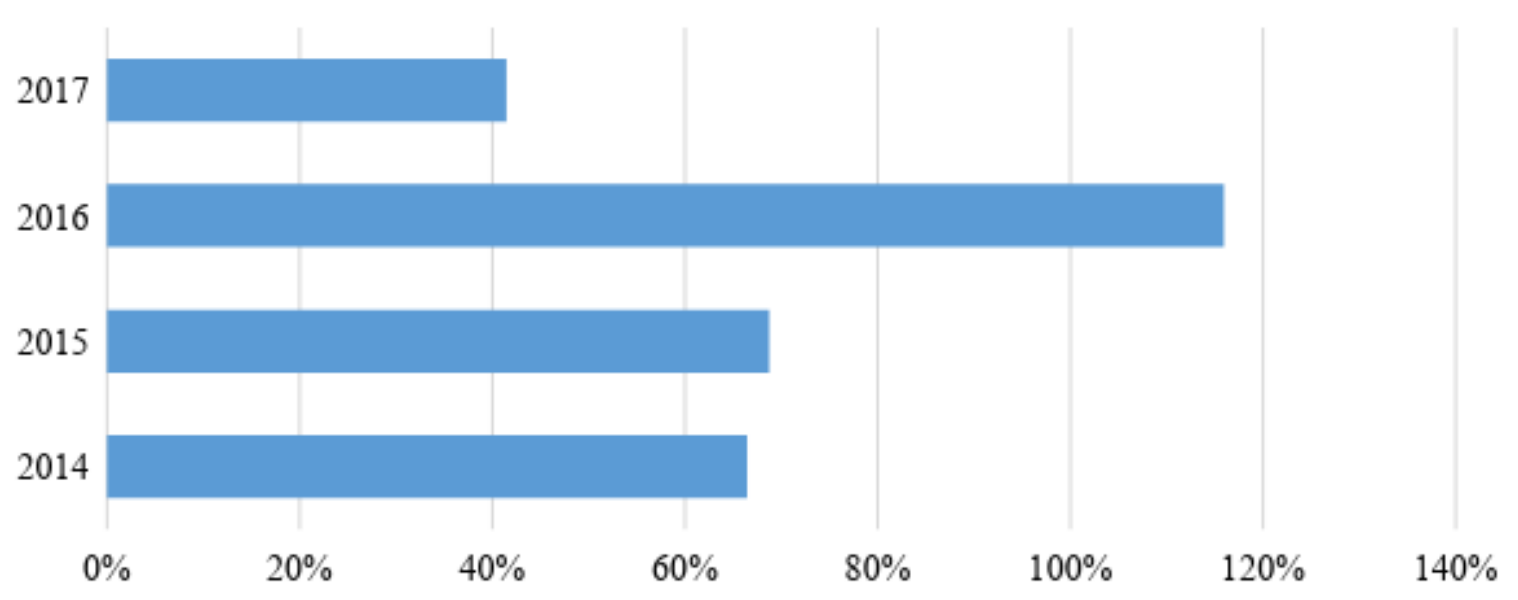

Fonte: Elaboração própria a partir de dados do CNJ (2017).

Gráfico 8. Porcentagem de cumprimento da Meta 6 pelo 2 grau do TJRO de 2014 a 2017.

\section{Cumprimento Meta 6 - 20 grau}

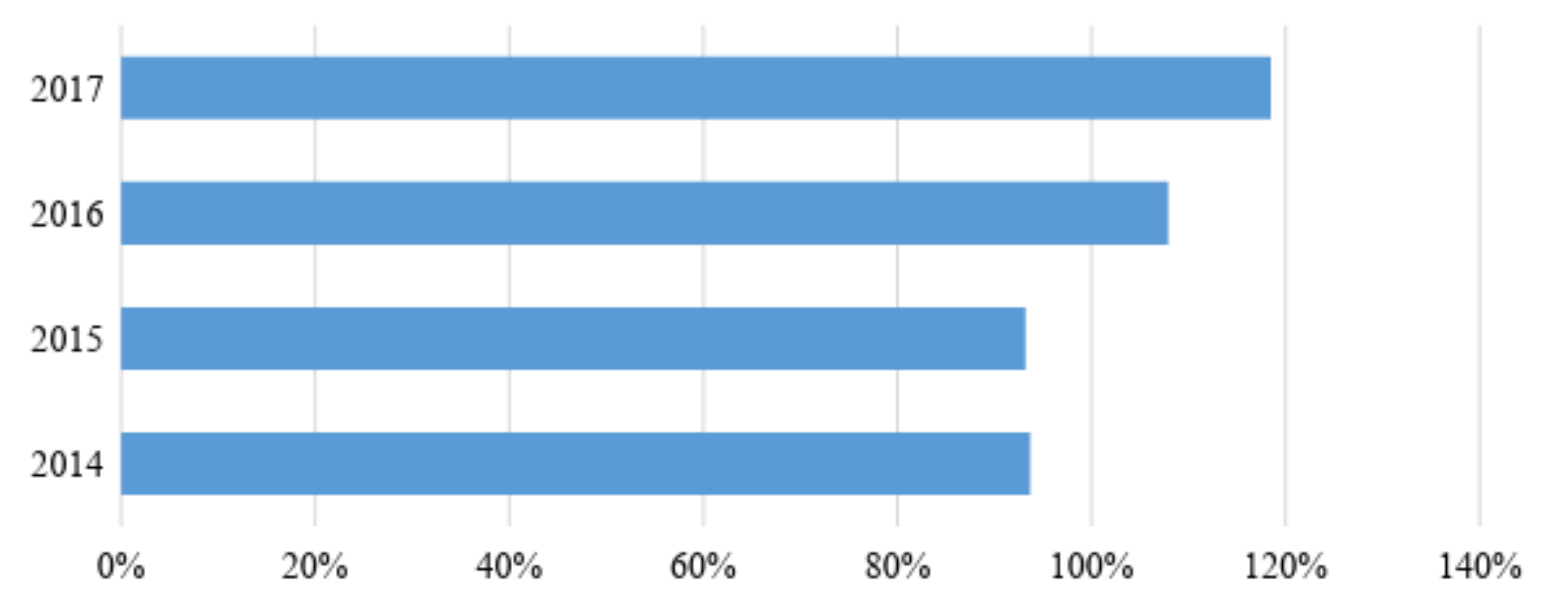

Fonte: Elaboração própria a partir de dados do CNJ (2017).

Os gráficos indicam um bom desempenho do TJRO, tanto que no ano de 2016 figurou em segundo lugar entre os tribunais de pequeno porte, conforme relatório da Justiça em Números do CNJ (2017b). Reflexo do empenho de membros, servidores e administração do tribunal, que investe em projetos e mecanismos para aferição e acompanhamento das metas, exemplo disso é o novo sistema, chamado de "Eolis", aliado ao banco de dados "Ventos", lançados em 10 de setembro de 2017 que, conforme noticiado no site do tribunal, automatizam os números de todo o tribunal, integrando os dados de forma padronizada (RONDONIA, 2017b).

Dessa forma o TJRO demonstra preocupação e cuidado para atender ao cumprimento das metas estabelecidas pelo $\mathrm{CNJ}$, o que também alcança as propostas do direito responsivo, uma vez que o estabelecimento de metas, que expressam os desejos da sociedade, representam uma aproximação entre poder judiciário e 
sociedade.

\section{CONSIDERAÇÕES FINAIS}

A visão de um judiciário distante da sociedade como grupo separado e inatingível está cada vez mais ultrapassada. Por exemplo, hoje as pessoas sabem o nome dos ministros do Supremo Tribunal Federal, hipótese jamais pensada anos atrás.

Essa aproximação faz com que a sociedade exija mais responsabilidade e eficiência do Poder Judiciário. Assim, o Conselho Nacional de Justiça surgiu em resposta, na chamada "reforma do judiciário".

As metas nacionais do CNJ são estabelecidas anualmente e expressam, ou pelo menos procuram, os anseios da sociedade quanto a priorização de julgamento, ao mesmo tempo em que buscam auxiliar os tribunais na direção de melhoramentos em tecnologia e aperfeiçoamento com pessoal.

Assim, quanto ao objetivo de identificar o modelo jurídico em que estão inseridas, neste trabalho foi constatado que, por conferir uma abertura para a sociedade, ainda que pequena, as metas do CNJ se caracterizam como movimento do direito responsivo, cabendo ao $\mathrm{CNJ}$ gerir as expectativas e promover a discussão entre os tribunais do país.

Isso porque aproxima a sociedade da gestão do judiciário e busca captar os anseios dos segmentos da sociedade em relação ao poder judiciário do país e retransmitir em forma de metas para os tribunais.

Em relação ao objetivo de verificar o desempenho da justiça comum estadual deste Estado, o estudo apontou que o Tribunal de Justiça do Estado de Rondônia, felizmente, demonstrou um bom desempenho no cumprimento das metas mais recorrentes do $\mathrm{CNJ}$, justificando o segundo lugar entre os tribunais de pequeno porte do país, obtido no ano de 2016.

Ainda foi verificado que o Tribunal de Justiça do Estado de Rondônia segue as diretrizes do direito responsivo, conforme orientação do $\mathrm{CNJ}$, ao disponibilizar consulta da sociedade (jurídica ou não) quanto a criação e alteração de metas. Além disso, o acompanhamento próximo - com a implantação de sistemas de informática específicos para a automatização dos números de todo o tribunal - demonstra o cuidado em cumprimento da meta e, por consequência, em uma boa prestação jurisdicional.

É inegável que ainda há muito que se avançar em relação ao direito responsivo no Brasil, no entanto, devem ser observados os pequenos avanços, destaque para a aproximação do judiciário com a sociedade por meio da implantação de metas nacionais e anuais, constatada neste trabalho.

A partir dessas iniciativas é que o modelo jurídico mais próximo do ideal (direito responsivo) poderá ser disseminado para outros segmentos da sociedade. Até porque para que o direito responsivo seja uma realidade 
concreta deve existir uma certa maturidade da população que só será alcançada paulatinamente, em pequenos passos.

\title{
THE GOALS OF THE NATIONAL COUNCIL OF JUSTICE AND THE RESPONSIVE LAW: AN ANALYSIS IN THE COURT OF JUSTICE OF THE STATE OF RONDÔNIA
}

\begin{abstract}
The National Council of Justice (CNJ) is an organ of control of the administrative and financial performance of the Judiciary and the fulfillment of the functional duties of the judges. One of the measures taken to fulfill its role is to set annual targets common to all courts. The goals focus on agility, social responsibility, modernization and prioritization of judgment. However, the $\mathrm{CNJ}$ is criticized at the same time as there is a requirement for the elaboration and implementation of public policies to improve judicial performance. An important function conferred on the $\mathrm{CNJ}$ is to evaluate and analyze the policies implemented. In this paper we analyze the legal model in which the goals proposed by the $\mathrm{CNJ}$ are inserted, through qualitative, exploratory and bibliographic research. Subsequently, we realize the identification of the performance of the Court of Justice of the State of Rondonnia (TJRO) in a quantitative, exploratory, descriptive and documentary manner. The results indicate that the implementation of goals by the $\mathrm{CNJ}$ has roots in responsive law, being a movement that offers a small participation of society. The TJRO demonstrated to perform well within the most recurrent goals, considering the commitment of members, servants and administration.
\end{abstract}

Keywords: Goals. CNJ. TJRO. Responsive right. Access to justice.

\section{REFERENCIAS}

ALMEIDA, Guilherme de. Acesso à justiça, direitos humanos e novas esferas da justiça. Contemporânea. Revista de Sociologia da UFSCAR. v. 2, n. 1 (2012). Janeiro - Junho de 2012. Disponível em: < http://emeron.tjro.jus.br/images/dhjus/Guilherme\%20de\%20Almeida\%20- 
\%20Direitos\%20humanos\%20e\%20acesso\%20\%20justia.pdf>. Acesso em 9 jul. 2017.

ARRABAL, Alejandro Knaesel; DIAS, Feliciano Alcide; SÁ, Priscila Zeni de. A decisão judicial e sua relação intersistêmica jurídica e econômica. Rev. SJRJ, Rio de Janeiro, v. 21, n. 41, p. 51-67, dez. 2014. Disponível em: < https://www.jrij.jus.br/sites/default/files/revista-sjrj/arquivo/PDF>. Acesso em 30 jul. 2017.

BRASIL. Constituição da República Federativa do Brasil de 1988. Disponível em: < http://www.planalto.gov.br/ccivil_03/constituicao/constituicaocompilado.htm>. Acesso em 23 de jul. 2017.

Emenda Constitucional no 45, de 2004 - Exposição de Motivos. Disponível em: < http://www2.camara.leg.br/legin/fed/emecon/2004/emendaconstitucional-45-8-dezembro-2004-535274exposicaodemotivos-149264-pl.html>. Acesso em: 23 jul. 2017.

Supremo Tribunal Federal. Ação direta de inconstitucionalidade no 3367/DF - Distrito Federal. Relator: Ministro Cezar Peluso. Pesquisa de Jurisprudência. Decisões. Julgamento do Pleno - Improcedente. 13/04/2005. Disponível em: $<$ http:/ /www.stf.jus.br/portal/processo/verProcessoAndamento.asp?incidente=2260590 >. Acesso em 30 de jul. 2017.

Ação Direta de Inconstitucionalidade no 4638/DF - Distrito Federal. Relator: Ministro Marco Aurélio. Pesquisa de Jurisprudência. Decisões. Liminar deferida em parte 19/12/2011. Disponível em: $<$ http:/ / www.stf.jus.br/portal/processo/verProcessoAndamento.asp?incidente=4125637>. Acesso em 30 de jul. 2017.

Mandado de Segurança no 34327/DF - Distrito Federal. Relator: Ministro Roberto Barroso. Pesquisa de Jurisprudência. Decisões. Denegada a segurança. 08/09/2016. Disponível em: < http://www.stf.jus.br/portal/processo/verProcessoAndamento.asp?incidente=5026298>. Acesso em 30 jul. 2017.

CASTELlO BRANCO, Luiza Szczerbacki. As metas do Conselho Nacional de Justiça e os esforços de planejamento estratégico no Tribunal de Justiça do Estado do Rio de Janeiro. 2013. Dissertação (Mestrado em Administração Pública), Fundação Getulio Vargas. Rio de Janeiro, 2013. Disponível em: < http://bibliotecadigital.fgv.br/dspace/bitstream/handle/10438/11021/Disserta\%C3\%A7\%C3\%A3o\%20Luiza \%20SCB.pdf?sequence=1>. Acesso em: 21 jul. 2017.

CIEGLINSKI, Thaís. Tribunais promovem ações participativas para metas de 2018. Agência CNJ de Notícias. 
Brasilia, 04/08/2017. Disponível em: <http://www.cnj.jus.br/noticias/cnj/85183-tribunais-promovem-acoesparticipativas-para-propor-metas-de-2018>. Acesso em: 5 ago. 2017.

CONSELHO NACIONAL DE JUSTIÇA. Brasília: [2017?] ]. Disponível em: < http://www.cnj.jus.br/sobre-ocnj>. Acesso em: 30 jul. 2017.

Justiça em Números. Brasília: [2017?]b. Disponível em:< http://www.cnj.jus.br/programas-e-acoes/pjjustica-em-numeros

>. Acesso em: 5 set. 2017

Metas Nacionais para 2016. Brasília: 2015. Disponível em:< http://www.cnj.jus.br/files/conteudo/arquivo/2016/03/f2ed1 labc4b5ddea9f673dec7fe39335.pdfs. Acesso em: 30 jul. 2017.

Metas Nacionais para 2017. Brasília: 2016a. Disponível em:< http://www.cnj.jus.br/files/conteudo/arquivo/2017/02/a2f4fc314db2ec5f39bb0615aba58b6a.pdf>. Acesso em: 30 jul. 2017.

Resolução no 70, de 18 de março de 2009. Dispõe sobre o Planejamento e a Gestão Estratégica no âmbito do Poder Judiciário e dá outras providências. Brasília: 2009. Disponível em: < http://www.cnj.jus.br///images/atos_normativos/resolucao/resolucao_70_18032009_22072014152617.pdf >. Acesso em 23 jul. 2017.

Resolução nº 221, de 10 de maio de 2016. Institui princípios de gestão participativa e democrática na elaboração das metas nacionais do Poder Judiciário e das políticas judiciárias do Conselho Nacional de Justiça. Brasilia: 2016b. Disponível em: <http://www.cnj.jus.br///images/atos_normativos/resolucao/resolucao_221_10052016_11052016144312. pdf>. Acesso em 30 jul. 2017.

Sobre as metas. Brasília: [2017?] c. Disponível em: < http://www.cnj.jus.br/gestao-eplanejamento/metas/sobre-as-metas >. Acesso em: 30 ago. 2017.

CONSULTOR JURÍDICO. Apoio a Sergio Moro chama a atenção em manifestações contra o governo. 16/08/2015. Disponível em: <http://www.conjur.com.br/2015-ago-16/apoio-sergio-moro-destaquemanifestacoes-governo $>$. Acesso em: 10 set. 2017.

DEMARCHI, Clovis. As metas do CNJ: controle e parâmetros para o prazo razoável do processo e o princípio da eficiência. Revista Eletrônica Direito e Política, Programa de Pós-Graduação Stricto Sensu em Ciências Jurídica da 
UNIVALI, Itajaí, $\quad$ v. $\quad 6, \quad$ n. $\quad 2$, $\quad 2^{\circ}$ quadrimestre de 2011. Disponível em:< http://siaiap32.univali.br/seer/index.php/rdp/article/view/6071/3338> Acesso em: 21 jul. 2017.

FREIRE, Geovana Maria Cartaxo de Arruda; BERNARDES, Marciele Berger; ROVER, Aires José. Políticas públicas responsivas do Conselho Nacional de Justiça: análise da ouvidoria. Revista Democracia Digital e Governo Eletrônico (ISSN 2175-9391), nn $\quad$ 5, p. 84-99, 2011. Disponível em: < http://www.buscalegis.ufsc.br/revistas/index.php/observatoriodoegov/article/view/34123/33071 >. Acesso em 30 jul. 2017.

NONET, Philippe; SELZNICK, Philip. Direito e Sociedade: a transição ao sistema jurídico responsivo. Tradução Vera Ribeiro. Rio de Janeiro: Revan, 2010.

RIBEIRO, Ludmila Mendonça Lopes; MACHADO, Igor Suzano. Repressão, autonomia e responsividade: o direito que se exerce nas delegacias de polícia no Brasil. Sociedade e Estado. Vol. 29 n¹ Brasília Jan./Apr. 2014. ISSN 0102-6992 Disponível em: <http://www.scielo.br/scielo.php?script=sci_arttext\&pid=S010269922014000100009>. Acesso em: 30 jul. 2017.

RONDONIA. Tribunal de Justiça do Estado de Rondônia. Participe da consulta pública sobre metas nacionais do Judiciário. TJRO Notícias. Porto Velho, 3.7.2017. Disponível em: $<$ https://www.tjro.jus.br/noticias/item/7760-participe-da-consulta-publica-sobre-metas-nacionais-dojudiciario >. Acesso em: 30 jul. 2017.

Ventos e Eolis: Corregedoria lança novas ferramentas que integram dados e melhoram o monitoramento de metas. TJRO Notícias. Porto Velho, 30.8.2017. Disponível em: $<$ https://www.tjro.jus.br/noticias/item/8034-ventos-e-eolis-sinalizam-revolucao-em-acompanhamento-denumeros-do-poder-judiciario-de-rondonia>. Acesso em: 5 set. 2017.

SILVA, Jeovan Assis da; FLORÊNCIO, Pedro de Abreu e Lima. Políticas judiciárias no Brasil: o Judiciário como autor de políticas públicas. Revista do Serviço Público. Brasília 62 (2): 119-136 Abr/Jun 2011. Disponível em: < https://revista.enap.gov.br/index.php/RSP/article/view/65>. Acesso em: 30 jul. 2017.

TAVARES, André Ramos. Reforma do judiciário no Brasil pós-88: (des)estruturando a justiça: comentários completos à EC n. 45/04. São Paulo: Saraiva, 2005. 
Quaestio Iuris

Trabalho enviado em 03 de novembro de 2018

Aceito em 05 de novembro de 2018 vol. 11, no. 04, Rio de Janeiro, 2018. pp. 3193-3210 DOI: $10.12957 /$ rqi.2018.38145

- 